\title{
LTE and GPS based Deca Band Printed Antenna for Cellular Mobile Handset Communication Applications
}

\author{
SYED SHERAZ-UL-HASAN MOHANI*, AND KAMRAN RAZA* \\ RECEIVED ON 29.11.2017 ACCEPTED ON 25.05.2018
}

\begin{abstract}
This paper presents novel mobile phone antenna for radiations simultaneously in ten frequency bands for applications of LTE (Long-Term Evolution), GPS (Global Positioning System), GSM (Global System for Mobile Communications), PCS (Public and Commercial Services), DCS (Distributed Control System), UMTS (Universal Mobile Telecommunications System) and WiMAX (Worldwide Interoperability for Microwave Access). The antenna demonstrates novel characteristics for resolving the challenge of simultaneous radiation capabilities for the GSM and GPS applications with frequencies of 850/900 and $1575 \mathrm{MHz}$ respectively, along with resonances at frequency band of $700 \mathrm{MHz}$ for LTE applications, 1800 and 1900 MHz for PCS and DCS applications, 2100 MHz for UMTS applications, 2400 and 2500 MHz for LTE applications and $3300 \mathrm{MHz}$ for WiMAX applications with $S_{11}=-6 \mathrm{~dB}$ matching criteria (VSWR 3:1). The antenna architecture comprises top and bottom copper layers embedded with monopole radiating element, branch line, slots and various stub lines. The desired operating bands are achieved in a compact area with overall dimensions of $0.8 \times 60 \times 120 \mathrm{~mm}$ for the height, width and length respectively of the antenna providing suitable platform for mobile handset applications. Omni-directional radiation pattern characteristics are achieved throughout the range of frequencies by designing the proposed antenna in monopole configuration. Proposed antenna is fabricated and results for the surface currents, s-parameters and 3D (Three-Dimensional) gain plots are illustrated for the proof of concept.
\end{abstract}

Key Words: Mobile Handset, Printed Antenna, Multiple Frequency Antenna, Long-Term Evolution.

\section{INTRODUCTION}

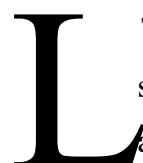

TE provides the essential and far reaching vital solutions for wireless communication systems high speed internet along with broader bandwidth and high throughput. During its initial stages in Europe, LTE has been assigned 1.8 and 2.6 GHz Bands. Currently due to the increase in the necessity of additional bandwidth the $790-865 \mathrm{MHz}$ band has been added to the LTE
Operating system. With these improved system performance characteristics, LTE is also implemented in mobile handheld devices for wireless communications.

LTE based systems for wireless communications and data transfer through electromagnetic waves can be implemented by designing antenna elements supporting resonances for the LTE frequency bands. Microstrip line 
with rectangular tuning stub for excitation can be designed for TRI band coverage of LTE bands of 758$865,1510,1940$ and 2488-2740 MHz [1]. Multi band with Dual Polarization is proposed [2], in which antenna system is a combination of six printed dipoles with vertical and horizontal polarization characteristics. A compact structure is formed by nesting the HP (Hewlett-Packard) elements between two cones of the VP element. WCDMA (Wideband Code-Division Multiple Access), CDMA800 and GSM900 are achieved with a vertical polarization segment, whereas with the combination of vertical and horizontal polarization elements the system can be operated for LTE bands. Dual bands of WLAN (Wireless Local Area Network) $802.11 \mathrm{a} / \mathrm{b} / \mathrm{g}$ operated at 2.4-2.4835/ 5.15-5.875 GHz and TD-LTE operated at 1.880-2.655 GHz are achieved by designing microstrip fed antenna and incorporating a rectangular slot, symmetrical inverted Lshaped metallic segments, a defected ground plane layer and fork shaped strip is illustrated in [3]. C-shaped metallic ground plane and loop parasitic shorted metallic strips are used to achieve LTE/WWAN multiband operation in mobile phone is presented in [4].

Combination of the two metallic segments generates multiple resonant modes in the $750-940 \mathrm{MHz}$ resonant band with 0.25 wavelength frequency modes at 750-940 $\mathrm{MHz}$ band to cover the GSM and LTE frequency bands. For meeting the requirement of multipurpose wireless communication systems with operating bands of GSM at 800 and $900 \mathrm{MHz}$ and LTE bands of 2300 and $2500 \mathrm{MHz}$, single antenna system with multiband characteristics is developed in [5], configured with monopole metallic element and coupled ground plane feeding line. Expedited development of mobile communication technologies has increased the demand on the design of wireless communication systems, where antennas for indoor wireless system are required to operate at multiple bands simultaneously. In this conjecture antenna is designed in
[6] with single port design for two different frequency bands of 800-960 and 1700-2700 MHz on printed circuit board technology for LTE applications, with return loss value of $-14 \mathrm{~dB}$ for both resonances. Slot meander patch technique is used to construct various antennas [7], to achieve multiple resonant frequencies for LTE TDD applications and by inculcating unequal meander line dimensions compared to equal meander lines, the antenna efficiency is increased. Channel capacity and data transmission rates are increased in the future and emerging wireless communication systems by incorporating MIMO (Multiple Input Multiple Output) technology [8]. For LTE and WiFi applications MIMO antenna system is developed in [9], with printed modified rectangular monopole radiators constructed with wideband strip lines. For radiation in six different frequency bands, tri-resonant mode antenna is designed in [10], having dual metallic stubs of $\mathrm{L}$ and $\mathrm{U}$ shaped stubs, with one stub used as parasitic radiation element and the other one consists of a metallic feeder embedded as a transmission line.

For multiband radiations covering LTE and GSM applications, various designs are proposed for compact handheld mobile devices. Three arrays are used for beam steering for $5 \mathrm{G}$ (Fifth Generation) mobile wireless communication by switching between the arrays [11]. MEMS (Microelectromechanical Systems) based on a concept of tunable capacitor can be used for implementation of reconfigurable antenna with frequency selectivity for fourth generation LTE configured mobile terminal applications [12]. Printed antenna for radiation in seven bands can be designed using loop element based radiator for the mobile phone applications utilizing circuits based on matching chip capacitors [13]. Mobile phones are designed with metal frame radiator element for LTE frequency bands using matching circuits and band pass filter [14]. To design the mobile antenna for multiband characteristics for simultaneously making WiFi and LTE

Mehran University Research Journal of Engineering \& Technology, Volume 38, No. 2, April, 2019 [p-ISSN: 0254-7821, e-ISSN: 2413-7219] 
applications operational, reconfigurable radiating element is also designed for selecting the frequency bands with slots embedded along with bandpass filter [15]. Metal rimmed architecture is used for radiations in LTE and GSM applications with three section configuration and inverted $\mathrm{F}$ radiating segments for proper radiation characteristics in the desired multibands [16].

Wireless communications for the LTE applications required wide bandwidth requirements that can be achieved by using metal bezel configuration along with monopole radiator for merging various eigen-modes [17]. Eight multibands can also be excited by using various branched lined parasitic ground segments along with Tshaped radiating elements in monopole antenna configuration for smart phone applications [18]. Next generation mobile phone systems require high speed data transfer along with enhanced channel capacity and mitigation of multipath fading, that can be achieved by implementing dual polarization capabilities using multiple loop radiator elements [19]. Mobile phone for broadband future services at $3.5 \mathrm{GHz}$ is designed with dual asymmetrically mirror loop antennas with MIMO eight element array compact size characteristics [20].

Various mobile phone antennas for wireless communication applications design parameters comparison along with the proposed antenna design is summarized in Table 1.
In this paper, compact printed antenna is proposed to support simultaneous radiations in ten frequency bands for applications of GPS, GSM, LTE, UMTS, DCS, PCS and WiMAX suitable for mobile handheld applications. The lower frequency bands of LTE 700, GSM 850, and GSM 900 and upper frequency bands of DCS 1700, PCS 1800 UMTS 2100, LTE 2400, LTE 2500 and LTE 2700 are achieved and inculcated in antenna system. The antenna system consist of top and bottom radiating layers with multiple metallic line segments configured with optimized dimensions in accordance with the desired bands.

\section{ANTENNA DESIGN}

The multiband planar printed antenna is developed on printed circuit board for mobile handsets applications as shown in Fig. 1. The antenna consists of top and bottom copper layers separated by substrate middle layer. Substrate used for the proposed antenna is FR4, having dielectric constant of 4.4 and height of $0.8 \mathrm{~mm}$. As seen from the Fig. 1, the top layer consists of radiating element that is fed from the bottom side from a feeding transmission line. Substrate middle layer size is of 120x60 mm with the bottom layer consisting of ground plane with size of 105x60 mm and several line segments and slots providing multiband resonant characteristics for the proposed antenna.

TABLE 1. COMPARISON OF MULTI- BAND GSM, WIMAX, LTE AND GPS CELLULAR ANTENNA WITH THE LITERATURE

\begin{tabular}{|c|c|c|c|}
\hline References & $\begin{array}{c}\text { Frequency } \\
(\mathrm{MHz})\end{array}$ & No. of Bands & Applications \\
\hline Wang and Cai [13] & $850 / 2100 / 2300$ & 7 & WWAN/LTE \\
\hline Chen and Zhao [14] & $700 / 2100$ & 2 & LTE \\
\hline Soltanpour and Fakharian [15] & $2100 / 2400$ & 7 & WiFi/LTE \\
\hline Liu et. al. [16] & $900 / 2100 / 2300$ & 8 & LTE/LTE/WLAN \\
\hline Tang and Du [18] & $700 / 850 / 2300 / 2500$ & 1 & MIMO \\
\hline Wong et. al. [20] & 3500 & 10 & GSM/GPS/LTE/WiMAX \\
\hline Proposed Work & $700 / 850 / 2500 / 3300$ & & 2 \\
\hline
\end{tabular}

Mehran University Research Journal of Engineering \& Technology, Volume 38, No. 2, April, 2019 [p-ISSN: 0254-7821, e-ISSN: 2413-7219] 
The detailed dimensions of the LTE and GPS based radiator illustrating the various slots and stubs embedded in the top and bottom layers are presented in Fig. 2, where the top and bottom layer details are demonstrated in Fig. 2(a-b) respectively. Microstrip line directly feeding the monopole strip comprises of two segments, where each segment is designed with constant uniform width, and individual responses are optimizing in terms of radiation characteristics and antenna efficiency. Line segment of 1.5 and $56.5 \mathrm{~mm}$ width and length respectively is embedded in the top layer for radiation of LTE $700 \mathrm{MHz}$ frequency band. The feed line is designed to match the overall response of multiband printed antenna. The details of the slots and lines embedded in the bottom layer is shown in Fig. 2(b), with the ground plane width optimized at $60 \mathrm{~mm}$. Various line segments with optimal values of 18 , 23 and $24.50 \mathrm{~mm}$ respectively are optimized for achieving the desired frequency bands for WiMAX, LTE and GPS applications.

The top Layer consists of the radiating element with length of $56.5 \mathrm{~mm}$ which is optimized to obtain the lower band $900 \mathrm{MHz}$. The bottom layer consists of multiple

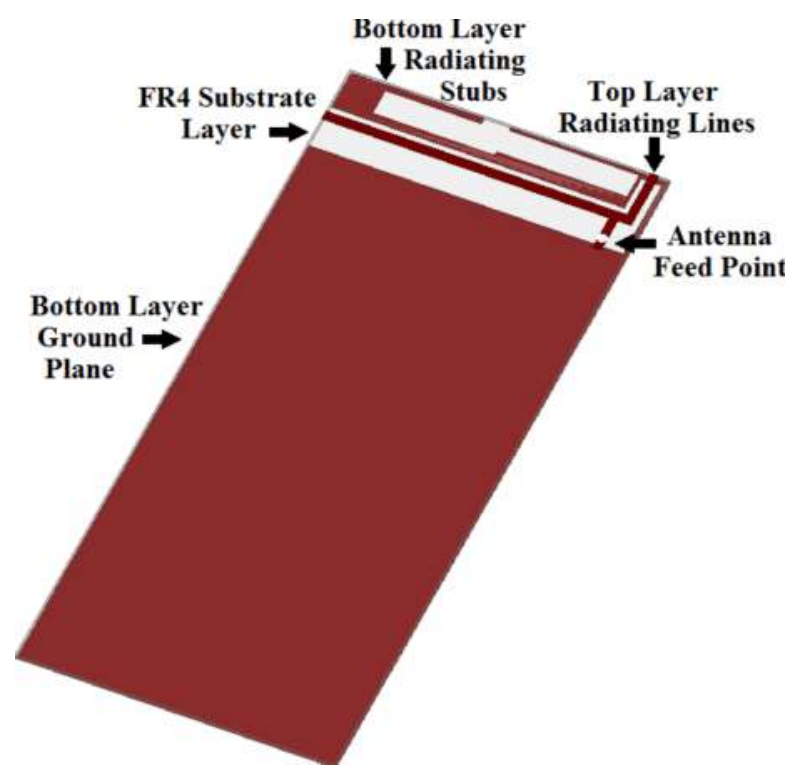

FIG. 1. PROPOSED GPS AND LTE BASED CELLULAR ANTENNA LABELED ARCHITECTURE slots to inculcate the rest of the frequencies, while line segments are introduced at bottom layer for controlling desired response and high performance. Length of line segments 6,4 and 5 are optimized at 7,23 and $18 \mathrm{~mm}$ respectively. The feed of length $6 \mathrm{~mm}$ with width of 1.50 $\mathrm{mm}$ is designed on top layer. Parametric analysis is performed for optimized values of the LTE and GPS based cellular planar antenna. The complete detailed labeled dimensions of the proposed multiband printed antenna are demonstrated in Table 2.

\section{SIMULATION AND ANALYSIS}

The LTE and GPS based cellular planar antenna is optimized designed and analyzed in CST Microwave Studio. Discrete port of $50 \mathrm{ohms}$ is connected to the feeding line for the excitation of the radiating structure.

The radiator element is optimized for GPS applications with its second band centered at $1575 \mathrm{MHz}$ while the higher frequency band for LTE is optimized at 2500 $\mathrm{MHz}$. The proposed radiator element is embedded with

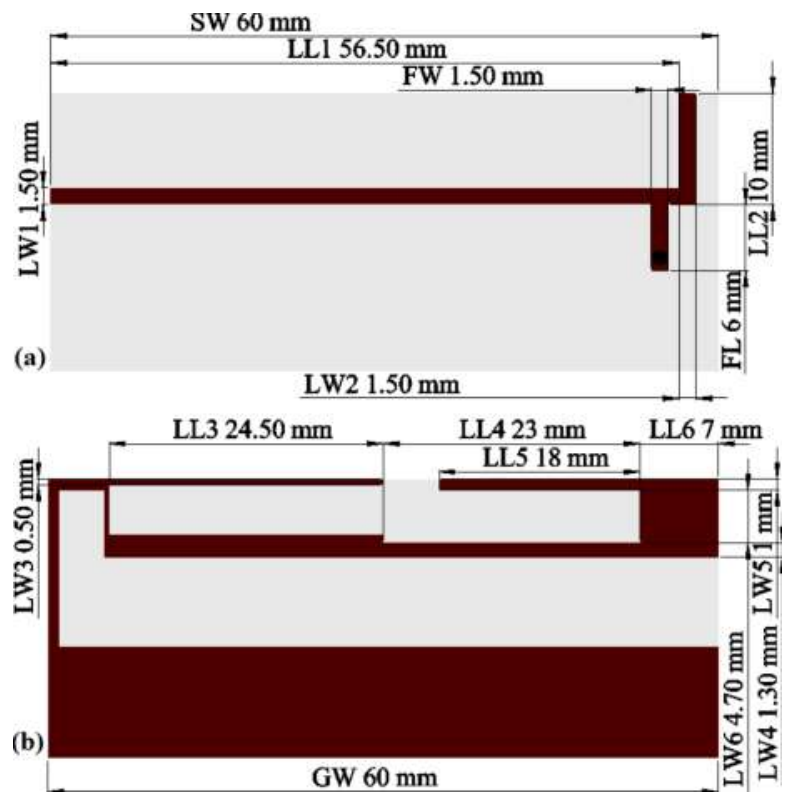

FIG. 2. DETAILED DIAGRAM OF THE GPS AND LTE CELLULAR PHONE ANTENNA ILLUSTRATING DIMENSIONS FOR (a) TOP, AND (b) BOTTOM LAYER

Mehran University Research Journal of Engineering \& Technology, Volume 38, No. 2, April, 2019 [p-ISSN: 0254-7821, e-ISSN: 2413-7219] 
various slots and stubs for providing radiation characteristics for UMTS at $2100 \mathrm{MHz}$ and WiMAX at $3300 \mathrm{MHz}$ with impedance bandwidth of $\mathrm{S}_{11}<-6$, demonstrating the complete frequency range from 500 $3500 \mathrm{MHz}$ in Fig. 3.

The frequency response of the GPS and LTE based cellular printed radiator is optimized for various line segment lengths and widths. GPS and DCS frequency bands are achieved with the impedance bandwidth of $\mathrm{S}_{11}<-6$, at $1575 \mathrm{MHz}$ for GPS applications and $1800 \mathrm{MHz}$ for DCS applications by parametrizing the third embedded slot element and optimizing for various lengths as demonstrated in Fig. 4. As seen in Fig. 4 the selection of value of GPS band is accordance to the value of DCS band if a higher value is selected our $1575 \mathrm{MHz}$ improves but the $1800 \mathrm{MHz}$ decreases with the return loss less than $-6 \mathrm{~dB}$ and same effect is incorporated at the 1900 $\mathrm{MHz}$ band. The dimensions of the fourth element embedded in the radiator element is parametrized as illustrated in Fig. 5 for achieving the frequency band at $1900 \mathrm{MHz}$ for the PCS applications by selecting segment width of $1.30 \mathrm{~mm}$ and impedance bandwidth of $\mathrm{S}_{11}<-6$.
Lower frequency bands of 700, 850 and $900 \mathrm{MHz}$ are optimized by controlling the dimensions of the first line segment element as demonstrated in Fig. 6, parametrizing three varied lengths of 56.5, 50.5 and $44.5 \mathrm{~mm}$, with the first frequency band of $700 \mathrm{MHz}$ having bandwidth

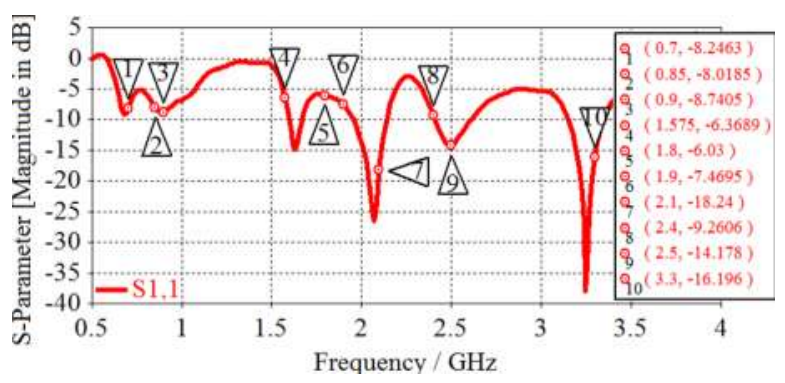

FIG. 3. $S_{I I}$ REPONSE OF LTE AND GPS BASED PROPOSED CELLULAR ANTENNA

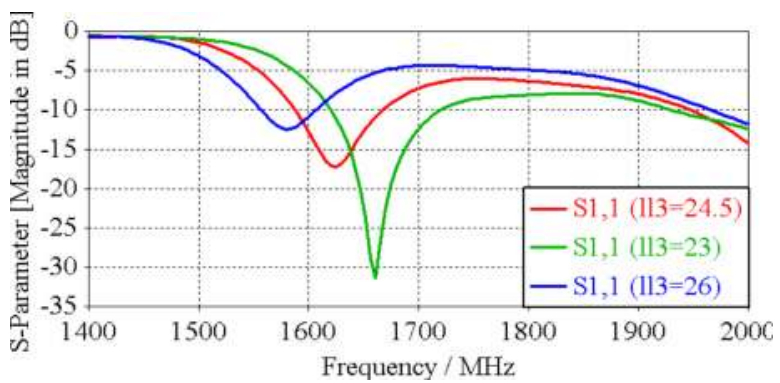

FIG. 4. OPTIMIZED $S_{U}$ REPONSE OF LTE AND GPS BASED CELLULAR ANTENNA DUE TO LENGTH OF THIRD ELEMENT

TABLE 2. MULTI- BAND GSM, WIMAX, LTE AND GPS CELLULAR ANTENNA DETAILS

\begin{tabular}{|c|c|c|}
\hline Label & Description & $\begin{array}{c}\text { Dimensions } \\
(\mathrm{mm})\end{array}$ \\
\hline LW5 & Fifth Line Width & 01.11 \\
\hline LL5 & Fifth Line Length & 01.30 \\
\hline LW4 & Fourth Line Width & 23.00 \\
\hline LL4 & Fourth Line Length & 10.00 \\
\hline LL2 & Second Line Length & 01.50 \\
\hline LW2 & Second Line Width & 60.00 \\
\hline GW & Ground Width & 60.00 \\
\hline SW & Substrate Width & 00.50 \\
\hline LW3 & Third Line Width & 06.00 \\
\hline FL & Feed Line & 01.50 \\
\hline FW & Feed Width & 00.50 \\
\hline LW1 & First Line Width & 56.50 \\
\hline LL1 & First Line Length & 04.70 \\
\hline LW6 & Sixth Line Width & 07.00 \\
\hline LL6 & Sixth Line Length & 24.50 \\
\hline LL3 & Third Line Length & \\
\hline
\end{tabular}

Mehran University Research Journal of Engineering \& Technology, Volume 38, No. 2, April, 2019 [p-ISSN: 0254-7821, e-ISSN: 2413-7219] 
optimized for $\mathrm{S}_{11}<-6 \mathrm{~dB}$. For covering the GSM bands of 850 and $900 \mathrm{MHz}$, the second frequency band of the radiator is optimized for achieving impedance bandwidth of $\mathrm{S}_{11}<-6 \mathrm{~dB}$. If the lower value is selected then it improves the return loss in $700 \mathrm{MHz}$ but at the same time it disturbs the next two frequency bands of 850 and $900 \mathrm{MHz}$, degrading the return loss at less than $-6 \mathrm{~dB}$ threshold for proper bandwidth.

Surface currents are demonstrated in Fig. 7, presenting the currents along various line segments are stubs at the top and bottom layers of the radiator. The bottom layer line segments L3 and L4 are responsible for the radiation in the lower band of $700 \mathrm{MHz}$, with maximum radiations along these line segments, as shown in the Fig. 7(a). The $900 \mathrm{MHz}$ is radiated form the top layer plane radiating element L1 as shown in Fig. 7(b), while the GPS band $(1575 \mathrm{MHz})$ is radiated from the bottom plane line segment L6 as shown in Fig. 7(c). The radiation for the higher frequencies of 1800,2400 and $2500 \mathrm{MHz}$ of the multiband printed antenna surface currents can be seen for frequencies in Fig. 7(d-f), with the radiations on the line segments of the bottom layer.

The 3D gain plot patterns of the multiband planar printed antenna is demonstrated in Fig. 8, showing radiation patterns of the multiband printed antenna in $3 \mathrm{D}$ at frequency bands of $850 \mathrm{MHz}$ for GSM applications, 1575 MHz for GPS applications, $1900 \mathrm{MHz}$ for PCS applications and 2100, 2500 and $2700 \mathrm{MHz}$ for LTE applications. As

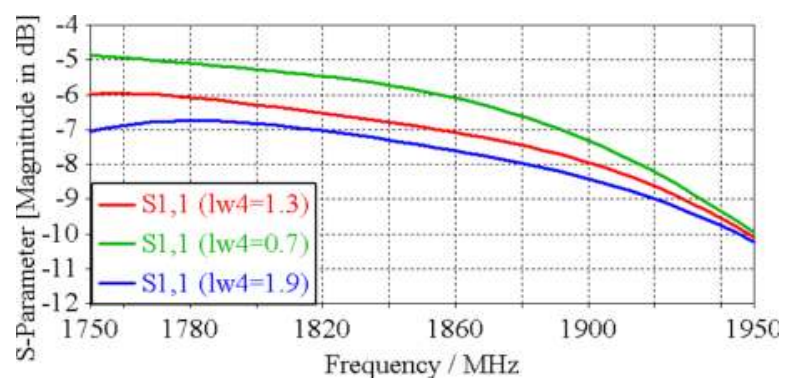

FIG. 5. OPTIMIZED $S_{11}$ REPONSE OF LTE AND GPS BASED CELLULAR ANTENNA DUE TO WIDTH OF FOURTH ELEMENT seen in Fig. 8(a), the radiation pattern at $850 \mathrm{MHz}$ frequency is having omni-directional pattern. Similarly, Fig.8(b) shows the radiation pattern of GPS band frequency (1575 MHz), while Fig.8(c) shows the GSM 900 $\mathrm{MHz}$ radiation pattern. From Fig. 8(d-f), radiations in the DCS 1800, 2400 and $2700 \mathrm{MHz}$ are demonstrated. The radiation patterns at the desired frequencies demonstrated a relatively omni-directional characteristic, which makes the proposed antenna suitable for mobile handset communication applications. The proposed multiband printed planar antenna demonstrates suitable gain values over the entire frequency band after optimization, as shown in Fig. 9. Gain vs. frequency plot demonstrates gain variation in the entire range of frequencies, with the higher frequencies of 2100, 2400 and $2700 \mathrm{MHz}$ illustrating higher gain values up to $4.11 \mathrm{~dB}$, whereas lower frequencies of 700, 850 and $900 \mathrm{MHz}$ bands exhibiting gain values up to $2.6 \mathrm{~dB}$. The fabricated prototype of the proposed antenna is shown in Fig. 10.

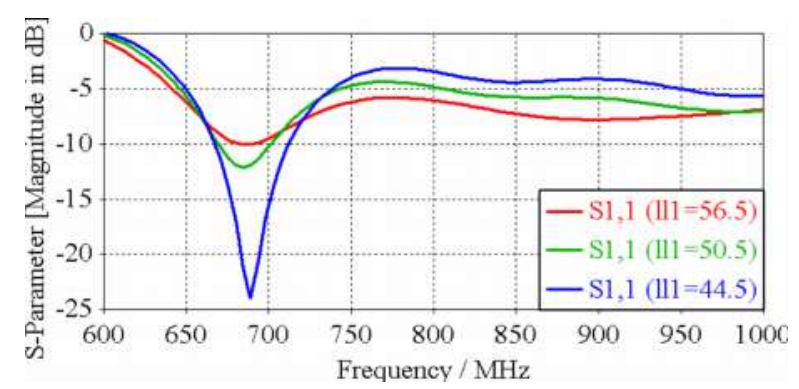

FIG. 6. OPTIMIZED $S_{11}$ REPONSE OF LTE AND GPS BASED CELLULAR ANTENNA DUE TO LENGTH OF FIRST ELEMENT

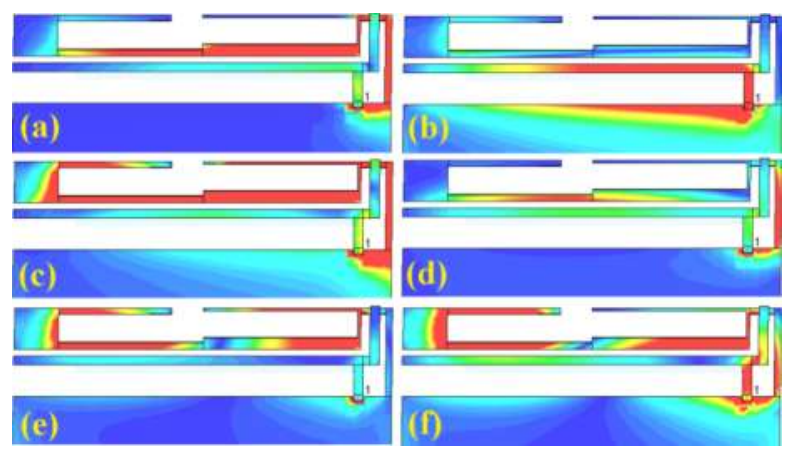

FIG. 7. SURFACE CURRENT PLOTS OF LTE AND GPS BASED CELLULAR ANTENNA AT FREQUENCY (a) 700, (b) 900, (c) 1575, (d) 1800, (e) 2100, (f) $3500 \mathrm{MHZ}$

Mehran University Research Journal of Engineering \& Technology, Volume 38, No. 2, April, 2019 [p-ISSN: 0254-7821, e-ISSN: 2413-7219] 


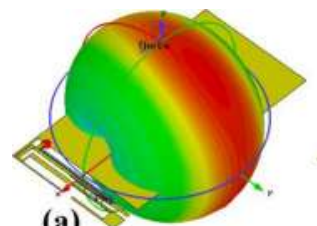

(a)

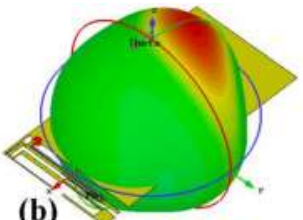

(b)

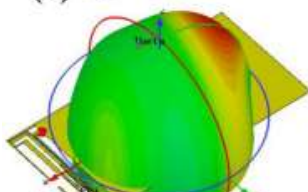

(c)

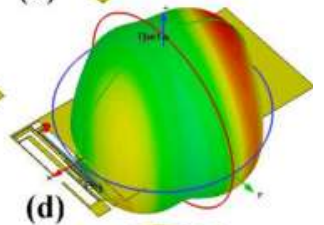

(d)

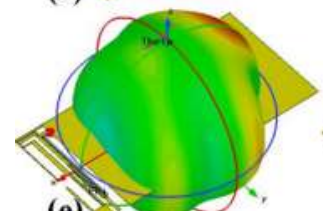

(e)

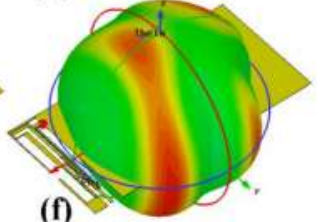

(f)

FIG. 8. THREE DIMENSIONAL GAIN PATTERNS OF LTE AND GPS BASED CELLULAR ANTENNA FOR THE FREQUENCIES OF (a) 850, (b) 1575, (c) 1900, (d) 2100, (e) 2500 AND (f) $3300 \mathrm{MHZ}$

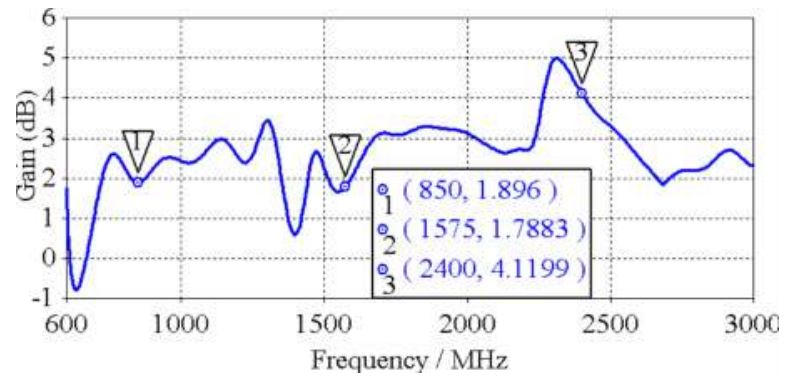

FIG. 9. GAIN VS FREQUENCY PLOT OF THE PROPOSED MULTIBAND PRINTED ANTENNA

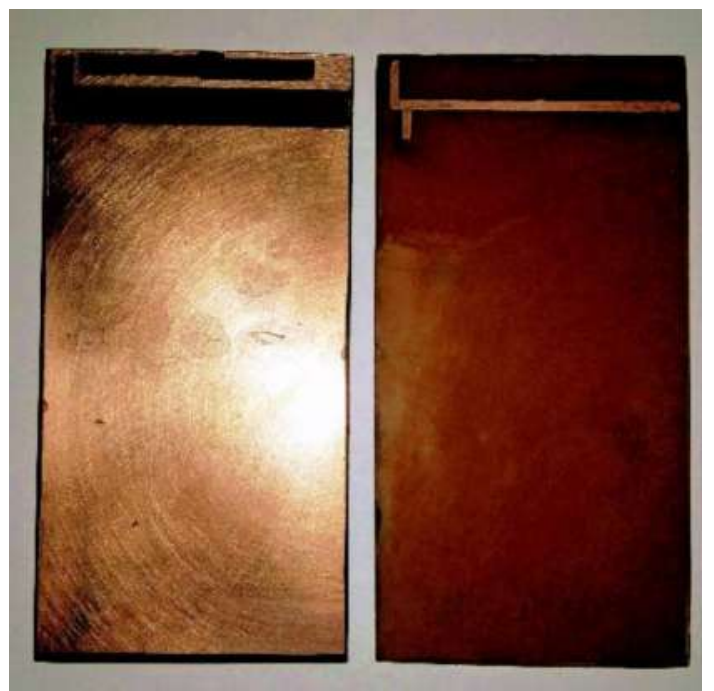

FIG. 10. PROPOSED GPS AND LTE BASED CELLULAR ANTENNA FABRICATED TOP AND BOTTOM LAYER PROTOTYPE

\section{CONCLUSION}

In this paper, a printed antenna for mobile handset has been presented for LTE, WiMAX, GPS and GSM application covering ten radiation frequency bands. The cellular radiator antenna system comprises various slots and stubs that are embedded on the bottom and top layers of the printed circuit board, where the individual line segment dimensions are designed and simulated for achieving the desired frequency bands. Top layer upper line segment is resonated for lower band operations. Bottom layer slots and line segments impacts for resonance of the higher frequencies. The frequency bands of GPS $1575 \mathrm{MHz}$, WiMAX 3500, GSM $850 \mathrm{MHz}$ and DCS $1800 \mathrm{MHz}$ are achieved by optimizing the line segments incorporated in the metallic top and bottom layers. The proposed cellular radiator demonstrates $-6 \mathrm{~dB}$ return loss validating better radiation efficiency characteristics while maintaining higher gain values for the upper bands of LTE and GSM as well as providing better bandwidth characteristics for the GPS frequency band that will provide better performance characteristic for the mobile handheld applications.

\section{ACKNOWLEDGEMENT}

Authors would like to acknowledge Omar Masood Khan, and Muhammad Khalid, Faculty of Engineering Sciences \& Technology, Iqra University, Karachi, Pakistan, for invaluable discussions and feedback.

\section{REFERENCES}

[1] Harroun, M.H., Ayad, H., Jomaa, J., "Design of a TriBand Microstrip Slot Antenna for LTE Application", International Conference on Digital Information and Communication Technology and Its Applications, pp. 165-167, May, 2015.

Mehran University Research Journal of Engineering \& Technology, Volume 38, No. 2, April, 2019 [p-ISSN: 0254-7821, e-ISSN: 2413-7219] 
[2] Dai, X., Wang, Z., Lian, C., Chen, X., and Wang, L., "Multiband and Dual-Polarized Omnidirectional Antenna for 2G/3G/LTE Application", IEEE Antennas and Wireless Propagation Letters, Volume 12, pp. 1492-1495, November, 2013.

[3] Chen, S., Dong, D., Liao, Z., Cai, Q., and Liu, G., "Compact Wideband and Dual Band Antenna for TDLTE and WLAN Application", Electronic Letters, Volume 50, No. 16, pp. 1111-1112, July, 2014.

[4] Lu, J., and Guo, J., "Small-Sized Octaband Monopole Antenna in an LTE/WWAN Mobile Phone", IEEE Antennas and Wireless Propagation Letters, Volume 13, pp. 548-551, March, 2014.

Chou, Y.J., Lin, G.S., Chen, J., Chen, L., and Houng, M., "Design of GSM/LTE Multiband Application for Mobile Phone Antennas", Electronic Letters, Volume 51, No. 17, pp. 1304-1306, August, 2015.

[6] Zhao, Y., "Dual Wideband Microstrip Antenna for LTE Indoor Base Station”, Electronic Letters, Volume 52, No. 8, pp. 576-578, April, 2016.

Elamin, N.I.M., Rahman, T.A., and Abdulrahman, A.Y., "New Adjustable Slote Meaner Patch Antenna for 4G Handheld Devices", IEEE Antennas and Wireless Propagation Letters, Volume 12, pp. 1077-1080, September, 2013.

[8] Bliss, D.W., Forsythe, K.W., and Chan, A.M., "MIMO Wireless Communication", Lincoln Laboratory Journal, Volume 15, No. 1, pp. 97-126, 2005.

[9] Moradikoralivand, A., Rahman, T.A., and Khalily, M., "Common Element Wideband MIMO Antenna System for WiFi/LTE Access-Point Application”, IEEE Antennas Wireless Propagation Letters, Volume 13, pp. 1601-1604, August, 2014.

[10] Lin, K.C., Lin, C.H., and Lin, Y.C., "Simple Printed Multiband Antenna with novel Parasitic-Element Design for Multistandard Mobile Phone Application”, IEEE Transactions on Antennas and Propagation, Volume 61, No. 1, pp. 488-491, January, 2013.

[11] Ojaroudiparchin, N., Shen, M., Zhang, S., and Pedersen, G.F., "A Switchable 3D-Coverage Phased Array Antenna Package for 5G Mobile Terminals", IEEE Antennas and Wireless Propagation Letters, Volume 15, pp. 1747-1750, February, 2016.
[12] Bahramzy, P., Jagielski, O., Svendsen, S., Olesen, P., and Pedersen, G.F., "Aspects of High-Q Tunable Antennas and Their Deployment for 4G Mobile Communications", IEEE Antennas and Propagation Magazine, Volume 58, No. 4, pp. 70-81, August, 2016.

[13] Wang, P., and Cai, Z., "A Planar Printed Loop Antenna With Less No-Ground Space for Hepta-band WWAN/ LTE Mobile Handset", Electronic Letters, Volume 52, No. 15, pp. 1284-1286, July, 2016.

[14] Chen, H., and Zhao, A., "LTE Antenna Design for Mobile Phone with Metal Frame", IEEE Antennas and Wireless Propagation Letters, Volume 15, pp. 1462-1465, December, 2015.

[15] Soltanpour, M., and Fakharian, M.M., "Compact Filtering Slot Antenna With Frequency Agility For WiFi/ LTE Mobile Applications", Electronic Letters, Volume 52, No.7, pp. 491-492, April, 2016.

[16] Liu, Y., Zhou, Y.M., Liu, G.F., and Gong, S.X., "HeptaBand Inverted-F Antenna for Metal-Rimmed Mobile Phone Applications", IEEE Antennas and Wireless Propagation Letters, Volume 15, pp. 996-999, October, 2015.

[17] Deng, C., Feng, Z., and Hum, S.V., "MIMO Mobile Handset Antenna Merging Characteristic Modes for Increased Bandwidth", IEEE Transactions on Antennas and Propagation, Volume 64, No. 7, pp. 2660-2667, July, 2016.

[18] Tang, R., and Du, Z., "Wideband Monopole Without Lumped Elements for Octa-Band Narrow-Frame LTE Smart Phone", IEEE Antennas and Wireless Propagation Letters, Volume 16, pp. 720-723, August, 2016.

[19] Zhao, X., Tian, B.N., Yeo, S.P., and Ong, L.C., "Wideband Segmented Loop Antenna with DualPolarized Omnidirectional Patterns for Mobile Platforms", IEEE Trasactions on Antennas and Propagation, Volume 65, No. 2, pp. 883-886, February, 2017.

[20] Wong, K.L., Tsai, C.Y., and Lu, J.Y., "Two Asymmetrically Mirrored Gap-Coupled Loop Antennas as a Compact Building Block for Eight-Antenna MIMO Array in the Future Smartphone", IEEE Transactions on Antennas and Propagation, Volume 65, No. 4, pp. 1765-1778, April, 2017. 